\title{
Association of distinct tetraspanins with MHC class II molecules at different subcellular locations in human immature dendritic cells
}

\author{
Anneke Engering ${ }^{1,2}$ and Jean Pieters ${ }^{1}$ \\ ${ }^{1}$ Basel Institute for Immunology, Grenzacherstrasse 487, CH-4005 Basel, Switzerland \\ 2Department of Cell Biology and Immunology, Vrije Universiteit, 1007 MB Amsterdam, The Netherlands
}

Keywords: antigen presentation, antigen processing, dendritic cells, MHC class II, MHC class II compartments, tetraspanins

\begin{abstract}
Dendritic cells have the capacity to trigger $T$ cell responses in lymphoid organs against antigens captured in the periphery. T cell stimulation depends on the ability of MHC class II molecules to present peptides at the cell surface that are acquired in MHC class II compartments. The high capacity of dendritic cells to stimulate $\mathrm{T}$ Iymphocytes is related to their ability to regulate the distribution of MHC class II molecules intracellularly. To analyze the molecular components involved in the generation of MHC class II-peptide complexes in human immature dendritic cells, mAb were raised against purified MHC class II compartments. One of the antigens turned out to be CD63, a member of the tetraspanin superfamily. CD63 localized exclusively intracellularly where it associated with peptide-loaded class II molecules. In contrast, the tetraspanins CD9, CD53 and CD81 associated with class II molecules at the plasma membrane. Selective association of distinct tetraspanins may be involved in the regulation of MHC class II distribution in human dendritic cells.
\end{abstract}

\section{Introduction}

The induction of an immune response requires the selective activation of antigen-specific T lymphocytes. The most potent antigen-presenting cells for the stimulation of these $T$ cells are dendritic cells (reviewed in 1). Derived from bone marrow, dendritic cells seed virtually all tissues. Several mechanisms are utilized by tissue dendritic cells to internalize a broad array of antigens $(2,3)$. However, they have a low capacity to activate $\mathrm{T}$ cells and hence are called 'immature' dendritic cells. Following an inflammation, dendritic cells leave the tissues via the draining lymph and migrate to lymph nodes. Concomitantly, dendritic cells mature and gain properties for efficient antigen presentation to $\mathrm{T}$ lymphocytes.

In immature dendritic cells most MHC class II molecules are localized intracellularly in MHC class II compartments $(2,3)$. In these organelles, peptides derived from antigens internalized via the endosomal/lysosomal pathway are loaded onto MHC class II molecules (4-7). During the lifespan of an $\mathrm{MHC}$ class II molecule, several chaperones influence its localization and residence time at different intracellular sites. After synthesis in the endoplasmic reticulum, the invariant chain (li) associates with the $\alpha$ and $\beta$ chain of MHC class II molecules, inhibiting premature peptide binding to $\mathrm{MHC}$ class II molecules $(8,9)$. Furthermore, at the trans-Golgi network, li functions in targeting $\alpha \beta$ complexes to MHC class II compartments (10-12). Here, the lumenal domain of $\mathrm{li}$ is degraded in distinct steps from its lumenal domain, most probably by the endosomal proteases cathepsin $S$ and/or $L$ $(13,14)$. The final processing product of $\mathrm{li}$ is CLIP, for class Il-associated peptide, that occupies the peptide binding groove. Exchange of CLIP for antigenic peptides is catalyzed by the chaperone HLA-DM (15-17). After loading, MHC class II-peptide complexes are transported to the cell surface for presentation to $\mathrm{T}$ lymphocytes.

Besides li and HLA-DM, several members of the tetraspan superfamily have been described to associate with class II molecules. Tetraspanins are molecules containing four 
membrane-spanning domains and short cytoplasmic tails that associate with a variety of molecules (reviewed in 18). At the plasma membrane of $\mathrm{B}$ lymphocytes large complexes are present consisting of $\mathrm{MHC}$ class II molecules, integrins, and the tetraspanins CD9, CD37, CD53, CD63, CD81 and CD82 (19-21). Furthermore, several tetraspanins are expressed in MHC class II compartments in B cells, where they form complexes with class II molecules and HLA-DM $(22,23)$. The function of tetraspanins on the plasma membrane and in class II compartments remains to be resolved.

In immature dendritic cells, several cell type-specific mechanisms contribute to the distribution of MHC class II molecules, as compared to other antigen-presenting cells. First, upon synthesis, part of the class II-li complexes are transported to the plasma membrane, after which they are rapidly internalized, $\mathrm{li}$ is degraded and peptides are loaded onto class II molecules (24). Second, at steady-state, MHC class II molecules recycle from the plasma membrane to intracellular sites $(25,26)$. Both newly synthesized and recycling $\mathrm{MHC}$ class II molecules can be loaded with peptides derived from internalized antigens (25). In mice, MHC class II distribution is regulated through li proteolysis (27), but the factors that contribute to MHC class II distribution in human dendritic cells are not known.

To analyze components possibly involved in $\mathrm{MHC}$ class II distribution, mAb were raised against purified $\mathrm{MHC}$ class II compartments from human immature dendritic cells. One of the antibodies recognized the tetraspanin CD63, which formed complexes with class II molecules in $\mathrm{MHC}$ class II compartments. Other members of the tetraspanins that associated with class II molecules were exclusively present at the cell surface. Distinct tetraspanins, by associating with $\mathrm{MHC}$ class II molecules at different subcellular sites, may be involved in the regulation of class II distribution in human dendritic cells.

\section{Methods}

\section{Antibodies and cells}

The following antibodies were used: 198 (IgG1), K31 (IgG1), anti-CD63 (IgG1; CLB, Amsterdam, The Netherlands), antiLamp-1 (H4A3, IgG1, ascites, anti-Lamp-2 (H4B4, IgG1, H4A3 and H4B4 developed by Drs August and Hildreth were obtained from the Development Hybridoma Bank maintained by the University of lowa, Department of Biological Sciences, lowa City, IA), anti-CD9 (kind gift of Dr M. Cella), anti-CD53 (Serotec, Oxford, UK), anti-CD81 (PharMingen, San Diego, $\mathrm{CA}$ ), anti-MHC class I (W6/32, IgG2b), and the following antibodies against MHC class II: L243 (IgG2a), DA6.231 and a rabbit polyclonal antibody (kind gift of Dr. H. Ploegh).

Dendritic cells were generated from human peripheral blood monocytes as described before (28). Monocytes separated by centrifugal elutriation, on Percoll gradients or using anti-CD14 beads (Dynal, Great Neck, NY) were cultured for 4-8 days in RPMI 1640 supplemented with 10\% FCS (Hyclone, Logan, UT), $50 \mathrm{ng} / \mathrm{ml}$ recombinant granulocyte macrophage colony stimulating factor (Leucomax; Sandoz, Basel, Switzerland) and $1000 \mathrm{U} / \mathrm{ml}$ recombinant $\mathrm{IL}-4$.

\section{Subcellular fractionation}

Subcellular fractionation of dendritic cells was performed as described $(3,5)$. Briefly, immature dendritic cells were homogenized, nuclei were removed and the postnuclear supernatant was treated with trypsin. Membranes were sedimented by centrifugation for $45 \mathrm{~min}$ at $100,000 \times g$ and electrophoresed for $90 \mathrm{~min}$ at $10.4 \mathrm{~mA}$ in a Ficoll gradient. Fractions of $0.5 \mathrm{ml}$ were collected from the top. The amount of protein was measured according to Bradford (29). The activity of $\beta$-hexosaminidase was assayed as described (30).

\section{Two-dimensional gel electrophoresis}

Two-dimensional isoelectric focusing (IEF)/SDS-PAGE was performed according to O'Farrell (31) with previously described modifications (32). IEF was performed using Resolyte, $\mathrm{pH}$ 4-8 (BDH, Poole, UK). Gels were subjected to silver staining according to Heukeshoven (33).

\section{Immunization and generation of hybridomas}

Two female BALB/c mice were immunized by s.c. injection in the hind limbs with $325 \mu \mathrm{g}$ protein of purified MHC class II compartments in $300 \mu \mathrm{l}$ PBS, emulsified in $300 \mu$ l complete Freund's adjuvant. Animals were boosted 3-4 times by injecting 100-150 $\mu \mathrm{g}$ protein in PBS in incomplete Freund's. Mice were sacrificed and regional lymph nodes removed and disrupted. Lymph node cells were fused with an excess of myeloma cells in 0.5 ml 50 PEG 1500 (Boehringer Mannheim, Mannheim, Germany) (34). Hybridomas were cultured in 96well flat-bottom plates in SF medium containing 10\% FCS, HAT (Gibco, Paisley, UK) and IL-6 (34).

\section{Metabolic labeling and immunoprecipitation}

Prior to metabolic labeling, cells were cultured for 20 min in RPMI without methionine and cysteine. Cells were labeled for the times indicated in the same medium containing 0.1$0.2 \mathrm{mCi} / \mathrm{ml}\left[{ }^{35} \mathrm{~S}\right] \mathrm{methionine} / \mathrm{cysteine}$ (Amersham Pharmacia Biotech) and 10\% dialyzed FCS. Cells were washed and chased in complete medium, supplemented with $2 \mathrm{mM}$ methionine and cysteine, or lysed directly. Lysis buffer contained $20 \mathrm{mM}$ HEPES, $\mathrm{pH} 7.5$, with $100 \mathrm{mM} \mathrm{NaCl}, 5 \mathrm{mM}$ $\mathrm{MgCl}_{2}$ and $1 \%$ Triton $\mathrm{X}-100$ with protease inhibitors $(10 \mu \mathrm{g} / \mathrm{ml}$ chymostatin, $10 \mu \mathrm{g} / \mathrm{ml}$ leupeptin, $10 \mu \mathrm{g} / \mathrm{ml}$ aprotinin, $10 \mu \mathrm{g} / \mathrm{ml}$ antipain, $10 \mu \mathrm{g} / \mathrm{ml}$ pepstatin and $1 \mathrm{mM} \mathrm{PMSF}$ ) (35). Alternatively, cells were lysed in CHAPS buffer [1\% CHAPS (Sigma, ST Louis, MO), 10 mM Tris- $\mathrm{HCl}, \mathrm{pH} 7.4,150 \mathrm{mM}$ $\mathrm{NaCl}, 1 \mathrm{mM} \mathrm{CaCl}_{2}, 1 \mathrm{mM} \mathrm{MgCl}_{2}$ and $0.02 \% \mathrm{NaN}_{3}$ with protease inhibitors] (19).

For immunoprecipitation, lysates were incubated with the indicated antibodies or for MHC class II immunoprecipitations with a mixture of L243 (ATCC, Rockville, MD), DA6.231 (kind gift from $\mathrm{Dr}$ C. Watts) and rabbit polyclonal antiserum (kind gift from $\mathrm{Dr} \mathrm{H}$. Ploegh) for $2-12 \mathrm{~h}$ at $4^{\circ} \mathrm{C}$, followed by $1 \mathrm{~h}$ incubation with $30 \mu$ I Protein A-Sepharose (Pharmacia). The immune complexes were washed 3 times with $1 \mathrm{ml}$ of lowsalt buffer (10 mM Tris- $\mathrm{HCl}, \mathrm{pH} 7.5,150 \mathrm{mM} \mathrm{NaCl}, 0.2 \%$ NP-40 and $2 \mathrm{mM}$ EDTA), 3 times with $1 \mathrm{ml}$ of high-salt buffer (10 mM Tris- $\mathrm{HCl}, \mathrm{pH} 7.5,500 \mathrm{mM} \mathrm{NaCl}, 0.2 \% \mathrm{NP}-40$ and $2 \mathrm{mM}$ EDTA) and twice with $1 \mathrm{ml}$ of $10 \mathrm{mM}$ Tris- $\mathrm{HCl}, \mathrm{pH} 7.5$. 
Immune complexes were eluted from the Protein A-Sepharose beads by incubation at $95^{\circ} \mathrm{C}$ for $5 \mathrm{~min}$ in Laemmli sample buffer (36), and subjected to SDS-PAGE, fluorography and autoradiography. Immune complexes from CHAPS lysates were washed 5 times in CHAPS buffer containing $0.5 \%$ CHAPS and separated under non-reducing conditions. When indicated, half of the immune complexes were incubated prior to elution with $10 \mathrm{mU}$ endo- $\beta$-galactosidase (Bacteroides

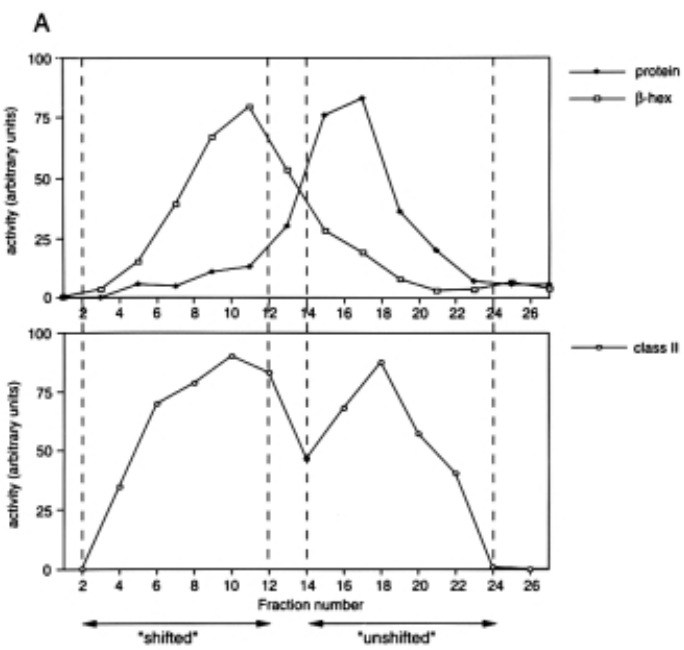

B

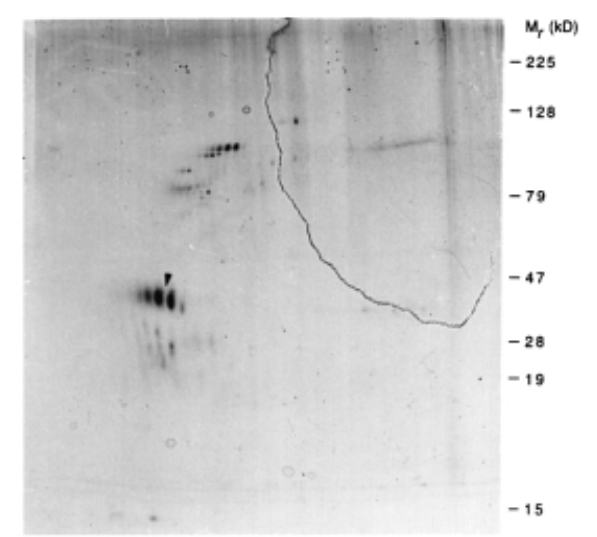

C

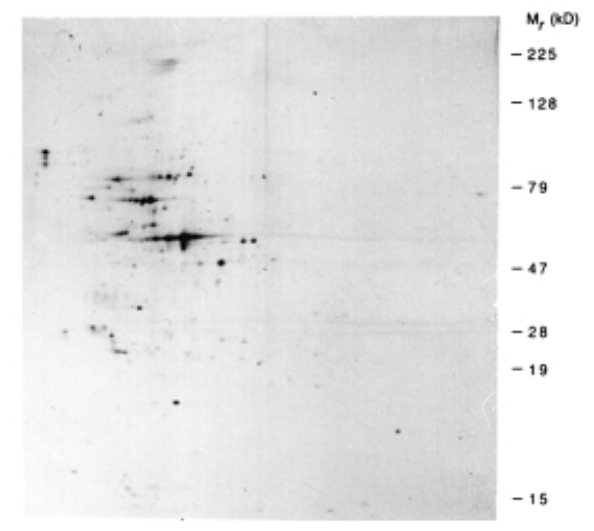

fragilis; Boehringer Mannheim) in $50 \mathrm{mM} \mathrm{Na}$ acetate ( $\mathrm{pH}$ 5.8) with $0.2 \mathrm{mg} / \mathrm{ml} \mathrm{BSA}$ for $24 \mathrm{~h}$ at $37^{\circ} \mathrm{C}$. As a control, the enzyme was omitted.

\section{Results}

\section{Analysis of antigens in MHC class // compartments}

To search for molecules possibly involved in MHC class IIrestricted antigen presentation in human dendritic cells, $\mathrm{MHC}$ class II compartments from immature dendritic cells were purified and used to immunize mice for the generation of $\mathrm{mAb}$. To isolate MHC class II compartments, immature dendritic cells were homogenized and subcellular organelles separated by electrophoresis (3,5). During electrophoresis, negatively charged organelles, such as lysosomes (as analyzed by $\beta$-hexosaminidase activity) and $\mathrm{MHC}$ class II compartments (as analyzed by immunoblotting using anti CIII antibodies), migrated towards the anode (Fig. 1A, 'shifted'). The bulk of organelles, including the MHC class II positive plasma membrane, remained unshifted (Fig. 1A, 'unshifted'). To compare the protein composition of the different pools, organelles were subjected to two-dimensional IEF/SDS-PAGE followed by silver staining. As shown in Fig. 1(B and C), different sets of polypeptides were resolved in the pooled 'shifted' and 'unshifted' fractions.

The purified MHC class II containing organelles were used to immunize mice as described in Methods. After immunization as described in Methods, mice were sacrificed and regional lymph nodes were fused with myeloma cells to raise hybridomas. Out of 994 hybridomas screened, 71 were reactive in immunoprecipitation (Table 1 ). As expected, most antibodies raised were generated against proteins known to be present in $\mathrm{MHC}$ class $\|$ compartments, such as $\mathrm{MHC}$ class II molecules, li, HLA-DM and the lysosomal membrane protein Lamp. Interestingly, a number of antibodies recognized MHC class I-like proteins, possibly members of the CD1 family. CD1 molecules are $\beta_{2}$-microglobulin-associated polypeptides that can present microbial lipid antigens and several members of this family are present in MHC class II compartments $(37,38)$. The majority of the hybridomas produced antibodies against intracellularly residing molecules, indicating the validity of the following procedure. Four $\mathrm{mAb}$ recognized unknown proteins.

Fig. 1. Isolation and characterization of MHC class II compartments from immature human dendritic cells. (A) Purification of MHC class II compartments from immature dendritic cells by organelle electrophoresis. Immature dendritic cells were homogenized and nuclei sedimented. After trypsinization, membranes were separated by subcellular organelle electrophoresis. After fractionation, the activity of $\beta$-hexosaminidase, the amount of protein and the presence of $\mathrm{MHC}$ class II molecules was determined. Fractions containing MHC class II molecules and $\beta$-hexosaminidase ('shifted') were pooled as well as fractions containing the bulk of proteins ('unshifted'), as indicated by the dotted lines. Membranes from pooled 'shifted' (B) and 'unshifted' (C) fractions were subjected to two-dimensional IEF/SDS-PAGE, followed by silver staining to analyze their protein composition. The basic end of the first dimension is shown on the right, the acidic end on the left. Arrowhead: $\alpha$ chain of MHC class II molecules. 
Table 1. Reactivity of hybridomas raised after immunization of mice with purified MHC class II compartments

\begin{tabular}{lc}
\hline & No. of hybridomas \\
\hline MHC class II or Ii & 46 \\
MHC class I or -related & 5 \\
Lamp-1 or -2 & 13 \\
Mannose receptor & 1 \\
HLA-DM & 2 \\
Unknown & 4 \\
Total & 71 \\
\hline
\end{tabular}

A

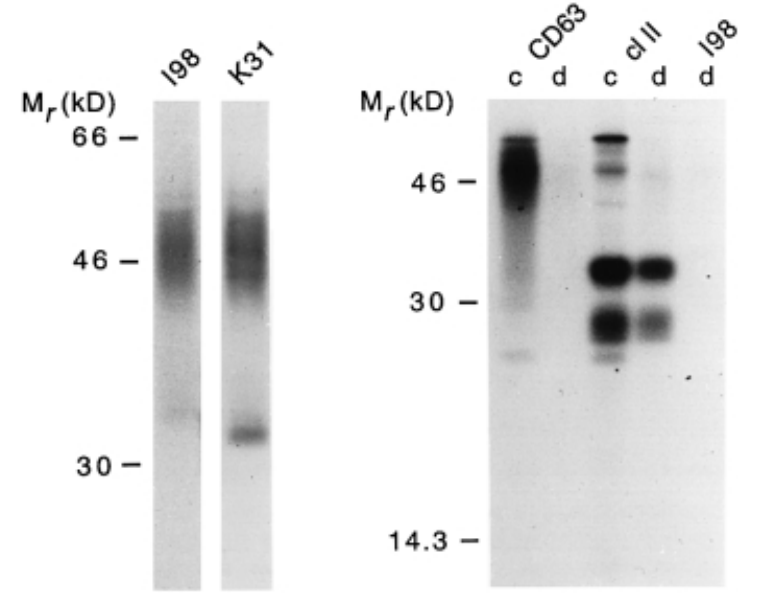

Fig. 2. Characterization of two $m A b$ raised against $M H C$ class II compartments. (A) Antigens recognized by two of the antibodies, 198 and K31. Immature dendritic cells were metabolically labeled for $14 \mathrm{~h}$ using $\left[{ }^{35} \mathrm{~S}\right]$ methionine/cysteine and lysed. Proteins were immunoprecipitated with 198 or K31 antibodies. (B) Identification of the antigen recognized by 198 and K31 as CD63. Cells were labeled as in (A) and lysed. Part of the lysate was depleted by three consecutive rounds of immunoprecipitation with 198. Control lysate (c) and depleted lysate (d) were incubated with anti-CD63 antibodies (CD63), anti-class II antibodies (cl II) or I98. Fluorographs after SDSPAGE are shown.

Two of the antibodies raised, 198 and K31, immunoprecipitated a polypeptide from $\sim 50 \mathrm{kDa}$ from immature dendritic cells that had been radio-labeled with [ $\left.{ }^{35} \mathrm{~S}\right]$ methionine/cysteine for $14 \mathrm{~h}$ (Fig. 2A). The antigens recognized by 198 and K31 migrated identically after two-dimensional IEF/ SDS-PAGE analysis (data not shown). To identify the antigen recognized by 198, re-immunoprecipitation as well as depletion experiments were performed using a variety of antibodies against proteins known to reside within MHC class II compartments. Cells were metabolically labeled with [ ${ }^{35}$ S]methionine/ cysteine for $14 \mathrm{~h}$ and lysed after which part of the lysate was depleted using 198 antibody (Fig. 2B). Among the various antibodies tested, antibodies to the CD63 antigen precipitated proteins of mol. wt $\sim 50 \mathrm{kDa}$ which were not precipitated from a lysate depleted with 198 (Fig. 2B). As a control, both nondepleted and depleted lysates were incubated with anti-class II antibodies, resulting in a similar recovery of MHC class II molecules (Fig. 2B). Thus, the mAb 198, generated after immunization with purified $\mathrm{MHC}$ class II compartments, recognized a polypeptide of $\sim 50 \mathrm{kDa}$, identified as CD63. CD63 is a member of the tetraspanins $(18,39)$ and is localized within $\mathrm{MHC}$ class II compartments of various antigen-presenting cells $(40,41)$.

\section{Subcellular localization of CD63 in MHC class // compartments}

The distribution of CD63 in human immature dendritic cells was analyzed after organelle electrophoresis and subsequent fractionation of metabolically labeled cells. Fractions containing $\beta$-hexosaminidase activity (Fig. 3: pool I, 'shifted', as in Fig. 1A) as well as fractions containing the bulk of proteins (pool II, 'unshifted', as in Fig. 1A) were pooled and lysed in $1 \%$ Triton $\mathrm{X}$-100-containing buffer. As a control for fractionation and pooling, part of the lysate was immunoprecipitated with antibodies against Lamp or MHC class I molecules, as marker proteins for lysosomes and for the plasma membrane respectively. As expected, Lamp was detected in 'shifted' fractions only while MHC class I in 'unshifted' fractions (Fig. 3B).

As shown in Fig. 3(A), CD63 was predominantly present in 'shifted' fractions. As described before (3), equivalent amounts of $\mathrm{MHC}$ class II molecules were present in class II compartments and at the plasma membrane (Fig. 3A).

CD63 is a member of the tetraspanin superfamily. Immature dendritic cells express readily detectable levels of CD9, a tetraspanin with broad tissue distribution first described in platelet granules, CD53, a lymphoid- and myeloid-restricted tetraspanin, and CD81, that is expressed by most cell types, consistent with the presence of a housekeeping promotor in the gene of this tetraspanin (18). The tetraspanins CD37 and CD82, present, for example, in B cells, were not detected in dendritic cells. The distribution of CD9, CD53 and CD81 was analyzed in 'shifted' and 'unshifted' fractions. As can be seen in Fig. 3(C), these tetraspanins were localized exclusively at the plasma membrane. Thus, CD63 is the only tetraspanin that localized within $\mathrm{MHC}$ class II compartments in dendritic cells.

Association of CD63 with MHC class II molecules in class II compartments

Members of the tetraspanin family can associate with other molecules and have been proposed to function as molecular facilitators (18-20). To analyze molecules possibly associated with CD63 in MHC class II compartments, metabolically labeled immature dendritic cells were lysed in CHAPScontaining buffer to preserve intermolecular interactions and proteins were immunoprecipitated using anti-CD63 antibodies. SDS-PAGE and fluorography revealed that besides the CD63 polypeptides, a protein of 35 as well as $28 \mathrm{kDa}$ were present in the CD63 (Fig. 4A). The molecular weight of these proteins is identical to those of MHC class $\| \alpha$ and $\beta$ chain (Fig. 4A). Indeed, re-immunoprecipitation using anti$\mathrm{MHC}$ class II antibodies showed that CD63 is associated with MHC class II molecules in immature dendritic cells (Fig. 4A).

Subsequently, the association of other tetraspanins with $\mathrm{MHC}$ class II molecules in immature dendritic cells was analyzed by re-precipitation. As is shown in Fig. 4(B), immunoprecipitation of CD9, CD53 and CD81 resulted in the coprecipitation of $\mathrm{MHC}$ class II molecules, although to a lesser 


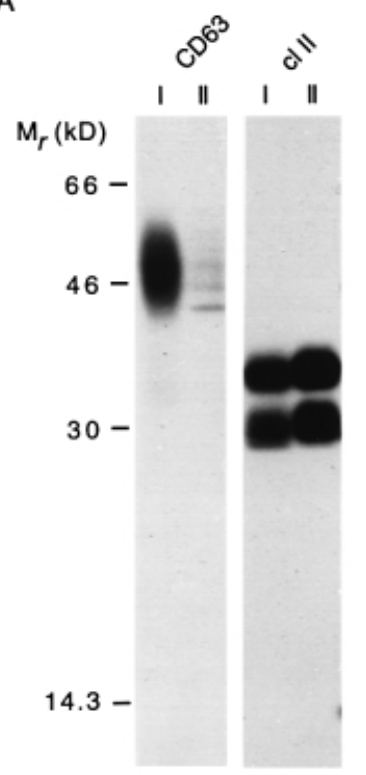

B

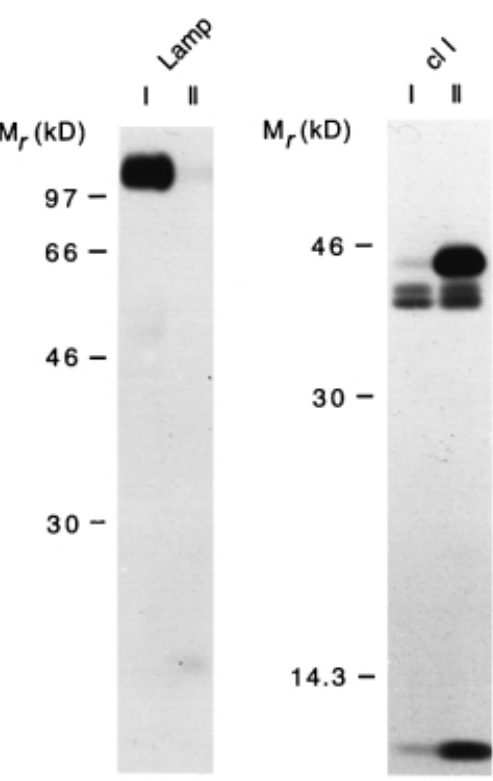

C

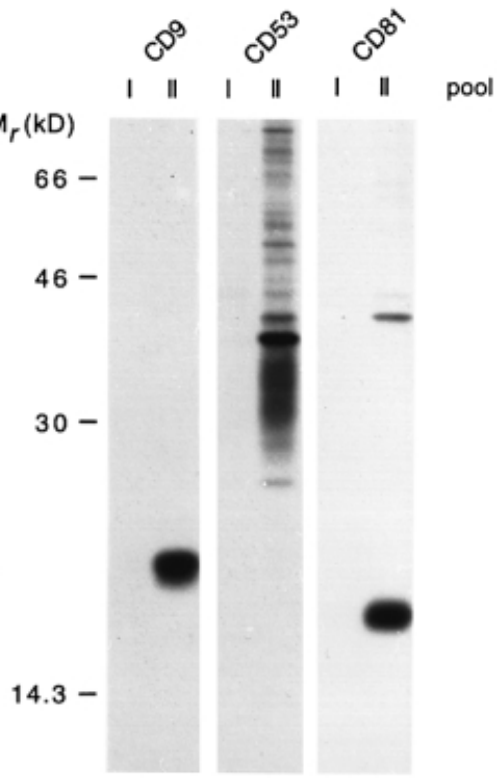

Fig. 3. Subcellular localization of CD63 and other tetraspanins. Immature dendritic cells were metabolically labeled with [35S]methionine/ cysteine for $14 \mathrm{~h}$, washed and incubated for $45 \mathrm{~min}$ in the absence of radiolabel. Cells were homogenized and trypsinized membranes were separated by organelle electrophoresis. Fractions containing $\beta$-hexosaminidase activity were pooled (Fraction I, shifted) as well as fractions containing the bulk of proteins (Fraction II, unshifted). Membranes were pelleted, lysed and immunoprecipitated with antibodies against the indicated molecules.

A

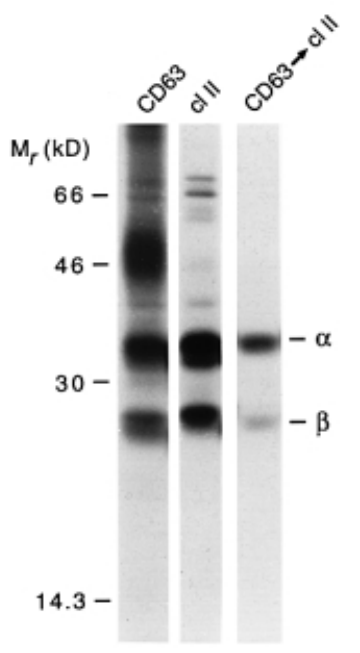

B

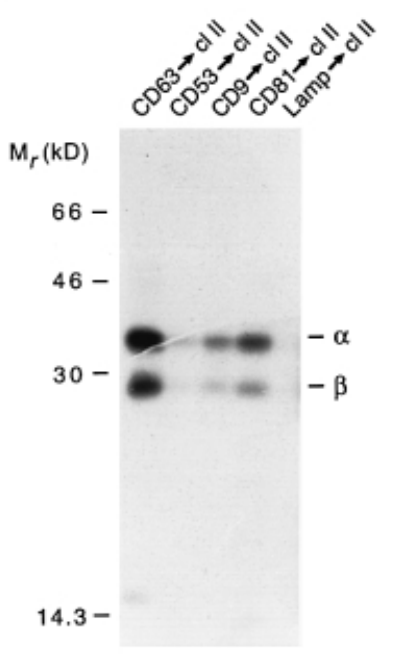

Fig. 4. Association of $\mathrm{MHC}$ class II molecules with tetraspanins in immature dendritic cells. (A) Association of proteins with CD63. Immature dendritic cells were metabolically labeled for $4 \mathrm{~h}$ with $\left.{ }^{35} \mathrm{~S}\right]$ methionine/cysteine, washed and cultured for $45 \mathrm{~min}$ without radiolabel. Cells were lysed in 1\% CHAPS-containing buffer followed by immunoprecipitation with anti-CD63 antibodies or anti-MHC class II antibodies. For re-precipitation (CD63 $\rightarrow \mathrm{cl}$ II), immune complexes after CD63 immunoprecipitation were resuspended in Triton X-100containing lysis buffer and precipitated with anti-class II antibodies. (B) Association of MHC class II molecules with tetraspanins. Immature dendritic cells were labeled, chased and lysed as in (A), followed by immunoprecipitation with antibodies against the indicated molecules and re-precipitation with anti-class II antibodies.

extent as compared to CD63. Interestingly, a small mol. wt polypeptide was found to be associated specifically with the class II molecules associated with CD63, which is likely to represent an li degradation fragment that is generated in a post-Golgi compartment $(5,7)$.

Although all analyzed members of the tetraspanin family form complexes with $\mathrm{MHC}$ class II molecules on dendritic cells, only CD63 is localized intracellularly. To directly analyze the subcellular localization of CD63-class II complexes, organelle electrophoresis of metabolically labeled immature dendritic cells was performed (Fig. 5A). Fractions were pooled as indicated in Fig. 5, lysed in CHAPS buffer and immunoprecipitated with anti-CD63 antibodies. SDS-PAGE analysis showed that CD63-class II complexes migrated at the position of the $\mathrm{MHC}$ class II compartments (Fig. 5B and C). No other polypeptides (other than li-related products) were detected to be associated with the CD63-MHC class II complex.

In MHC class II compartments, peptides are loaded onto class II molecules; these organelles therefore contain both empty and peptide-loaded class II complexes $(5,42,43)$. To analyze with which cohort of class II complexes CD63 was associated, the SDS stability of the CD63-associated class II molecules was analyzed. Class II molecules occupied with peptides are resistant to denaturing by SDS and migrate as a dimer of $\sim 55 \mathrm{kDa}$ following SDS-PAGE (44). Metabolically labeled and chased immature dendritic cells were lysed in CHAPS buffer followed by immunoprecipitation using anti-CD63 antibodies and re-precipitated using anticlass II antibodies. As a control, immunoprecipitation with class II antibodies was performed. After mild denaturation of the immunoprecipitated material and analysis by SDS-PAGE, SDS-stable $\alpha \beta$ dimers were readily detected (Fig. 6). MHC 
A

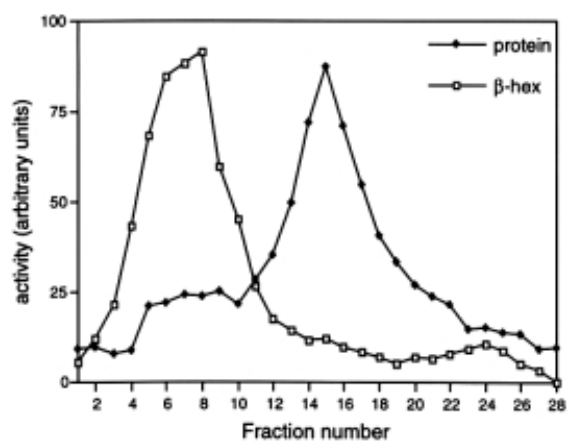

B

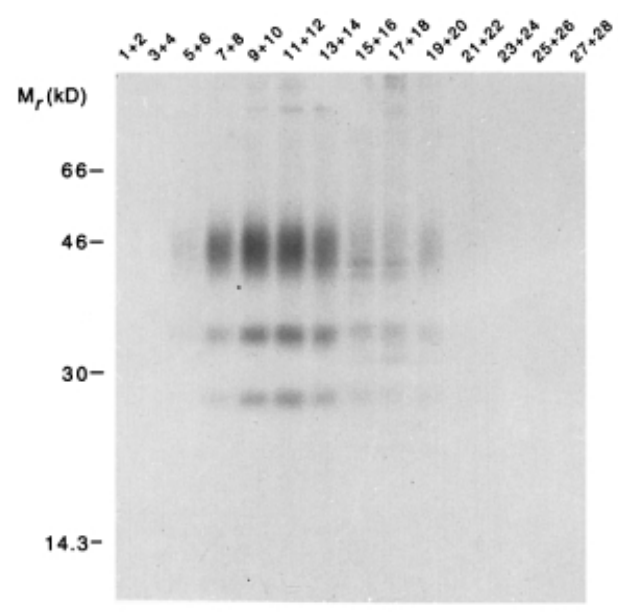

C

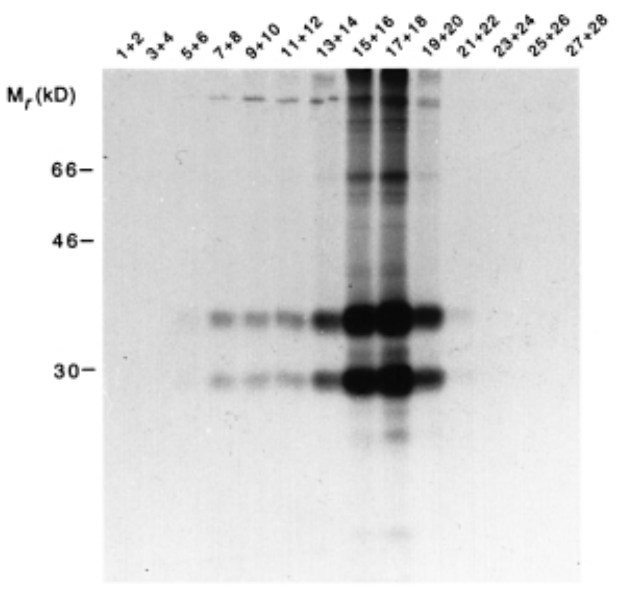

Fig. 5. Distribution of CD63-associated MHC class II molecules. Immature dendritic cells were metabolically labeled for $4 \mathrm{~h}$, washed and cultured for $45 \mathrm{~min}$. Cells were homogenized and subjected to organelle electrophoresis. After fractionation, the amount of $\beta$ hexosaminidase (open squares) and the amount of protein (closed diamonds) was determined (A). Every two fractions were pooled and CHAPS-containing lysis buffer was added. Proteins were immunoprecipitated using anti-CD63 antibodies (B) or anti-class II antibodies (C).

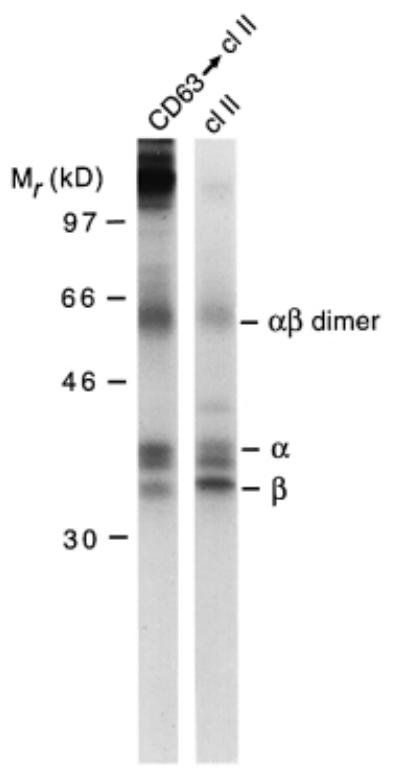

Fig. 6. SDS stability of CD63-associated MHC class II molecules. Immature dendritic cells were labeled, chased and lysed as in Fig. 5(A). Proteins were immunoprecipitated with anti-CD63 antibodies, resuspended in Triton X-100-containing lysis buffer and re-precipitated with anti-class $\|$ antibodies. Alternatively, proteins were immunoprecipitated using anti-class II antibodies. Proteins were eluted under mildly denaturing conditions prior to analysis by SDS-PAGE.

class II molecules associated with CD63 also occurred as dimers, indicating that CD63-class II complexes contain peptide-loaded MHC class II molecules (Fig. 6). Notably, the relative amount of SDS-stable complexes was larger in CD63associated $\mathrm{MHC}$ class II molecules as compared to the amount in the total pool of MHC class II molecules.

\section{Discussion}

Efficient loading of antigenic peptides on MHC class II molecules occurs in specialized organelles, MHC class II compartments (4-6). This process is highly efficient in immature dendritic cells, antigen-presenting cells that can initiate $T$ cell responses against foreign antigens (1). In these cells, MHC class II molecules are expressed at high levels, and recycle between the cell surface and the intracellular MHC class II compartment $(25,26)$. Antigens are internalized into dendritic cells by various endocytic mechanisms, ensuring a steady flow of potential antigenic peptides to the class II loading compartment $(2,3)$.

The mechanisms that are involved in the regulation of peptide loading onto $\mathrm{MHC}$ class II molecules remain poorly characterized. In a search for molecules possibly involved in class II-restricted antigen presentation, we have used highly purified MHC class II compartments from human immature dendritic cells as an antigen for the generation of mAb. Given their superior antigen processing and presentation capacity, usage of dendritic cells for such an approach may be of advantage over other, less professional antigen-presenting cells. 
The validity of the approach used was indicated by the fact that numerous hybridomas were raised against known components of $\mathrm{MHC}$ class II compartments. In addition, four other hybridomas were raised of which two recognized CD63, a member of the tetraspanin protein family (39). CD63 exclusively associated with $\mathrm{MHC}$ class II molecules intracellularly, whereas other tetraspanins formed complexes with $\mathrm{MHC}$ class II molecules at the cell surface of dendritic cells.

In contrast to the situation in human immature dendritic cells, in B lymphocytes complexes of a variety of tetraspanins have been reported to which $\mathrm{MHC}$ class II molecules are assembled both at the cell surface (CD9, CD37, CD53, CD63, CD81 and CD82) and intracellularly (CD82) (19,20,22,23). Tetraspanins were also found in B cell and dendritic cellderived exosomes, vesicles that are believed to be released upon fusion of a minority of MHC class II compartments with the plasma membrane $(22,45,46)$. It remains to be established if these tetraspanins in exosomes are derived from the plasma membrane or from an intracellular pool.

The exclusive intracellular presence of CD63 in immature dendritic cells indicates that class II molecules have to be released from CD63 prior to their cell-surface expression. Notably, CD63-associated class II molecules were complexed with peptides, and it is tempting to speculate that in dendritic cells class II molecules shuttle from CD63 to the tetraspanins that reside at the cell surface. The coordinated association of class II complexes with CD63 intracellularly, and the tetraspanins CD9, CD53 and CD81 at the plasma membrane in dendritic cells may contribute to class II-restricted antigen presentation to $\mathrm{T}$ lymphocytes.

CD63 has been localized to a wide variety of distinct intracellular organelles whose content or membrane molecules are discharged after appropriate stimuli. These include the cytolytic granules of cytotoxic T lymphocytes $(47,48)$, the Weibel-Palade bodies of vascular endothelial cells (49), the secretory granules of neutrophiles and basophiles $(50,51)$, as well as those from megakaryocytes and platelets (52). All of these organelles have a proteolytic environment and CD63 may actually function as a chaperone involved in protecting membrane proteins from degradation, in the case of dendritic cells MHC class II-peptide complexes. In this context it is interesting to note that CD63 mainly localizes to internal vesicles of $\mathrm{MHC}$ class II compartments $(22,53)$. Alternatively, CD63 could function in targeting peptide-loaded class II molecules away from the peptide-editing function of $H L A$ $\mathrm{DM}$, which is localized to the outer membrane of $\mathrm{MHC}$ class Il compartments (53).

In conclusion, in human dendritic cells tetraspanins could, by selectively associating with $\mathrm{MHC}$ class molecules at distinct sites, be involved in the regulation of $\mathrm{MHC}$ class II distribution.

\section{Acknowledgements}

We thank M. Cella and A. Lanzavecchia for discussion and critical review of the manuscript, G. Ferrari and C. Schwaerzler for advise on the hybridoma technology, D. Scheidegger and L. Kuhn for expert technical assistance, and H. L. Ploegh for antibodies. The Basel Institute for Immunology was founded and is supported by F. Hoffmann-La Roche \& Co., Ltd, Basel, Switzerland.

\section{Abbreviations}

IEF isoelectric focusing

li invariant chain

\section{References}

1 Cella, M., Sallusto, F. and Lanzavecchia, A. 1997. Origin, maturation and antigen presenting function of dendritic cells. Curr. Opin. Immunol. 9:10.

2 Sallusto, F., Cella, M., Danieli, C. and Lanzavecchia, A. 1995. Dendritic cells use macropinocytosis and the mannose receptor to concentrate macromolecules in the major histocompatibility complex class II compartment: downregulation by cytokines and bacterial products. J. Exp. Med. 182:389.

3 Engering, A. J., Cella, M., Fluitsma, D., Brockhaus, M., Hoefsmit, E. C. M., Lanzavecchia, A. and Pieters, J. 1997. The mannose receptor functions as a high capacity and broad specificity antigen receptor in human dendritic cells. Eur. J. Immunol. 27:2417.

4 Amigorena, S., Drake, J. R., Webster, P. and Mellman, I. 1994. Transient accumulation of new MHC molecules in a novel endocytic compartment in B lymphocytes. Nature 369:113.

5 Tulp, A., Verwoerd, D., Dobberstein, B., Ploegh, H. L. and Pieters, J. 1994. Isolation and characterization of the intracellular MHC class II compartment. Nature 369:120.

6 West, M. A., Lucocq, J. M. and Watts, C. 1994. Antigen processing and class II MHC peptide-loading compartments in human B-lymphoblastoid cells. Nature 369:147.

7 Ferrari, G., Knight, A. M., Watts, C. and Pieters, J. 1997. Distinct intracellular compartments involved in invariant chain degradation and antigenic peptide loading of major histocompatibility complex (MHC) class II molecules. J. Cell Biol. 139:1433

8 Roche, P. A. and Cresswell, P. 1990. Invariant chain association with HLA-DR molecules inhibits immunogenic peptide binding. Nature 345:615.

9 Teyton, L., O'Sullivan, D., Dickson, P. W., Lotteau, V., Sette, A., Fink, P. and Peterson, P. A. 1990. Invaiant chain distinguishes between the exogenous and endogenous antigen presentation pathways. Nature 348:39.

10 Bakke, O. and Dobberstein, B. 1990. MHC class II-associated invariant chain contains a sorting signal for endosomal compartments. Cell 63:707.

11 Lotteau, V., Teyton, L., Peleraux, A., Nilsson, T., Karlsson, L., Schmid, S. L., Quaranta, V. and Peterson, P. A. 1990. Intracellular transport of class II MHC molecules directed by invariant chain. Nature 348:600.

12 Pieters, J., Bakke, O. and Dobberstein, B. 1993. The MHC class II-associated invariant chain contains two endosomal sorting signals within its cytoplasmic tail. J. Cell Sci. 106:831.

13 Bevec, T., Stoka, V., Pungercic, G., Dolenc, I. and Turk, V. 1996. Major histocompatibility complex class II-associated p41 invariant chain fragment is a strong inhibitor of lysosomal cathepsin $\mathrm{L}$. J. Exp. Med. 183:1331.

14 Riese, R. J., Wolf, P. R., Bromme, D., Natkin, L. R., Villadangos, J. A., Ploegh, H. L. and Chapman, H. A. 1996. Essential role for cathepsin S in MHC class II-associated invariant chain processing and peptide loading. Immunity 4:357.

15 Denzin, L. K. and Cresswell, P. 1995. HLA-DM induces CLIP dissociation from MHC class II alpha beta dimers and facilitates peptide loading. Cell 82:155.

16 Sloan, V. S., Cameron, P., Porter, G., Gammon, M., Amaya, M., Mellins, E. and Zaller, D. M. 1995. Mediation by HLA-DM of dissociation of peptides from HLA-DR. Nature 375:802.

17 Sherman, M. L., Weber, B. L., Datta, R. and Kufe, D. W. 1990 Transcriptional and posttranscriptional regulation of macrophagespecific colony stimulating factor gene expression by tumor necrosis factor. Involvement of arachidonic acid metabolites [published erratum appears in J. Clin. Invest. 1990; 85(4):following 1338]. J. Clin. Invest. 85:442.

18 Maecker, H. T., Todd, S. C. and Levy, S. 1997. The tetraspanin superfamily: molecular facilitators. FASEB J. 11:428. 
19 Rubinstein, E., Le Naour, F., Lagaudriere-Gesbert, C., Billard, M. Conjeaud, H. and Boucheix, C. 1996. CD9, CD63, CD81, and CD82 are components of a surface tetraspan network connected to HLA-DR and VLA integrins. Eur. J. Immunol. 26:2657.

20 Szollosi, J., Horejsi, V., Bene, L., Angelisova, P. and Damjanovich, S. 1996. Supramolecular complexes of MHC class I, MHC class II, CD20, and tetraspan molecules (CD53, CD81, and CD82) at the surface of a B cell line JY. J. Immunol. 157:2939.

21 Angelisova, P., Hilgert, I. and Horejsi, V. 1994. Association of four antigens of the tetraspans family (CD37, CD53, TAPA-1, and R2/C33) with MHC class II glycoproteins. Immunogenetics 39:249.

22 Escola, J. M., Kleijmeer, M. J., Stoorvogel, W., Griffith, J. M. Yoshie, O. and Geuze, H. J. 1998. Selective enrichment of tetraspan proteins on the internal vesicles of multivesicular endosomes and on exosomes secreted by human B-lymphocytes. J. Biol. Chem. 273:20121.

23 Hammond, C., Denzin, L. K., Pan, M., Griffith, J. M., Geuze, H. J. and Cresswell, P. 1998. The tetraspan protein CD82 is a resident of MHC class II compartments where it associates with HLA-DR, -DM, and -DO molecules. J. Immunol. 161:3282.

24 Saudrais, C., Spehner, D., de la Salle, H., Bohbot, A., Cazenave, J. P., Goud, B., Hanau, D. and Salamero, J. 1998. Intracellular pathway for the generation of functional MHC class II peptide complexes in immature human dendritic cells. J. Immunol. 160:2597.

25 Cella, M., Engering, A., Pinet, V., Pieters, J. and Lanzavecchia, A 1997. Inflammatory stimuli induce accumulation of MHC class II complexes on dendritic cells. Nature 388:782.

26 Pierre, P., Turley, S. J., Gatti, E., Hull, M., Meltzer, J., Mirza, A. Inaba, K., Steinman, R. M. and Mellman, I. 1997. Developmental regulation of $\mathrm{MHC}$ class II transport in mouse dendritic cells. Nature 388:787

27 Pierre, P. and Mellman, I. 1998. Developmental regulation of invariant chain proteolysis controls $\mathrm{MHC}$ class II trafficking in mouse dendritic cells. Cell 93:1135.

28 Sallusto, F. and Lanzavecchia, A. 1994. Efficient presentation of soluble antigen by cultured human dendritic cells is maintained by granulocyte/macrophage colony-stimulating factor plus interleukin-4 and downregulated by tumor necrosis factor- $\alpha$. J. Exp. Med. 179:1109.

29 Bradford, M. 1976. A rapid and sensitive method for the quantitation of microgram quantities of protein utilizing the principle of protein-dye binding. Anal. Biochem. 72:248

30 Koldovsky, O. and Palmieri, M. 1971. Cortisone-evoked decrease of acid $\beta$-galactosidase, $\quad \beta$-glucuronidase, $N$-acetyl- $\beta$ glucosaminidase and acrylsulphatase in the ileum of suckling rats. Biochem. J. 125:697.

31 O'Farrell, P. H. 1975. High resolution two-dimensional electrophoresis of proteins. J. Biol. Chem. 250:4007.

32 Lefkovits, I., Young, P., Kuhn, L., Kettman, J., Gemmell, A. Tollaksen, S., Anderson, L. and Anderson, N. 1985. Use of largescale two-dimensional ISODALT gel electrophoresis systems in immunology. In Lefkovits, I. and Pernis, B., eds, Immunolgical Methods III, p. 163. Academic Press, Orlando, FL.

33 Heukeshoven, J. and Dernick, R. 1988. Improved silver staining procedure for fast staining in PhastSystem development unit. I. Staining of sodium dodecyl sulfate gels. Electrophoresis 9:28.

34 Harlow, E. and Lane, D. 1988. Antibodies: A Laboratory Manual. Cold Spring Harbor Laboratory Press, Cold Spring Harbor, NY.

35 Pieters, J., Horstmann, H., Bakke, O., Griffiths, G. and Lipp, J. 1991. Intracellular transport and localization of Major
Histocompatibility Complex class II molecules and associated invariant chain. J. Cell Biol. 115:1213.

36 Laemmli, U. K. 1970. Cleavage of structural proteins during the assembly of the head of bacteriophage T4. Nature 227:680.

37 Sugita, M., Porcelli, S. A. and Brenner, M. B. 1997. Assembly and retention of CD1b heavy chains in the endoplasmic reticulum. J. Immunol. 159:2358.

38 Porcelli, S. A. and Brenner, M. B. 1997. Antigen presentation: mixing oil and water. Curr. Biol. 7:R508.

39 Metzelaar, M. J., Wijngaard, P. L., Peters, P. J., Sixma, J. J. Nieuwenhuis, H. K. and Clevers, H. C. 1991. CD63 antigen. A novel lysosomal membrane glycoprotein, cloned by a screening procedure for intracellular antigens in eukaryotic cells. J. Biol. Chem. 266:3239.

40 Peters, P. J., Neefjes, J. J., Oorschot, V., Ploegh, H. L. and Geuze, H. J. 1991. Segregation of MHC class II molecules from MHC Class I molecules in the Golgi complex for transport to lysosomal compartments. Nature 349:669.

41 Nijman, H. W., Kleijmeer, M. J., Ossevoort, M. A., Oorschot, V. M. J., Vierboom, M. P. M., van de Keur, M., Kenemans, P., Kast, W. M., Geuze, H. J. and Melief, C. J. M. 1995. Antigen capture and $\mathrm{MHC}$ class II compartments of freshly isolated and cultures human blood dendritic cells. J. Exp. Med. 182:163.

42 Pieters, J. 1997. MHC class II restricted antigen presentation. Curr. Opin. Immunol. 9:89.

43 Wolf, P. R. and Ploegh, H. L. 1995. How MHC class II molecules acquire peptide cargo: Biosynthesis and trafficking through the endocytic pathway. Annu. Rev. Cell Dev. Biol. 11:267.

44 Germain, R. N. and Hendrix, L. R. 1991. MHC Class II structure, occupancy and surface expression determined by postendoplasmic reticulum antigen binding. Nature 353:134.

45 Raposo, G., Nijman, H. W., Stoorvogel, W., Liejendekker, R., Harding, C. V., Melief, C. J. and Geuze, H. J. 1996. B lymphocytes secrete antigen-presenting vesicles. J. Exp. Med. 183:1161.

46 Thery, C., Regnault, A., Garin, J., Wolfers, J., Zitvogel, L., RicciardiCastagnoli, P., Raposo, G. and Amigorena, S. 1999. Molecular characterization of dendritic cell-derived exosomes. Selective accumulation of the heat shock protein hsc73. J. Cell Biol. 147:599

47 Peters, P. J., Borst, J., Oorschot, V., Fukuda, M., Krahenbuhl, O., Tschopp, J., Slot, J. W. and Geuze, H. J. 1991. Cytotoxic T lymphocyte granules are secretory lysosomes, containing both perforin and granzymes. J. Exp. Med. 173:1099.

48 Griffiths, G. M. 1995. The cell biology of CTL killing. Curr. Opin. Immunol. 7:343.

49 Vischer, U. M. and Wagner, D. D. 1993. CD63 is a component of Weibel-Palade bodies of human endothelial cells. Blood 82:1184

50 Tapper, H. and Grinstein, S. 1997. Fc receptor-triggered insertion of secretory granules into the plasma membrane of human neutrophils: selective retrieval during phagocytosis. J. Immunol. 159:409

51 Calafat, J., Janssen, H., Knol, E. F., Weller, P. F. and Egesten, A 1997. Ultrastructural localization of Charcot-Leyden crystal protein in human eosinophils and basophils. Eur. J. Haematol. 58:56.

52 Heijnen, H. F., Debili, N., Vainchencker, W., Breton-Gorius, J., Geuze, H. J. and Sixma, J. J. 1998. Multivesicular bodies are an intermediate stage in the formation of platelet alpha-granules. Blood 91:2313.

53 Kleijmeer, M. J., Raposo, G. and Geuze, H. J. 1996. Characterization of MHC class II compartments by immunoelectron microscopy. Methods 10:191. 